\title{
How Can Millians Believe in Superheroes?
}

\author{
Juliana Faccio Lima*
}

Received: 13 April 2020 / Accepted: 24 October 2020

\begin{abstract}
What is the content of beliefs expressed by sentences with fictional names? Millianism has notoriously struggled to give a satisfactory answer to this question. Some Millians have argued that fictional names are empty names. But such a view entails that the belief that Superman has impressive superpowers and the belief that Aquaman has impressive superpowers have the same content, contrary to our intuitions. Others have argued that fictional names refer to fictional entities. But this view has a long-standing problem, Frege's Puzzle, and many philosophers are skeptical that Millians have successfully addressed it, despite commendable efforts. In this paper, I put forward a different Millian Theory of fictional proper names that by-passes these and other objections related to belief content. The novelty of my proposal partially rests on a distinction I draw between semantic content and belief content - as opposed to a distinction between belief content and belief state or a way of grasping the content, as it is commonly found in Millian accounts - in a framework where belief contents are not part of the meaning of names.
\end{abstract}

Keywords: Belief content, empty names; Frege's Puzzle; belief ascription, Millianism.

* Ashoka University

https://orcid.org/0000-0001-7842-6229

- Department of Philosophy, Plot No. 2, Rajiv Gandhi Education City, National Capital Region P.O.Rai, Sonepat Haryana-131029, India

$\bowtie$ jfacciolima@gmail.com

(c) The Author. Journal compilation (C) The Editorial Board, Organon F.

This article is distributed under the terms of the Creative Commons Attribution-NonCommercial 4.0 International Public License (CC BY-NC 4.0). 


\section{Introduction}

Millianism is the view that the semantic content or the meaning of proper names is only its referent. ${ }^{1}$ For instance, Millianism holds that the name 'Marie Curie' means Marie Curie because 'Marie Curie' refers to her. In this view, names function like tags to get hold of an object.

Millianism is typically paired with Standard Compositionality Principles to get the meaning of sentences. Such principles hold that the meaning of a complex expression, such as sentences, is determined solely by the meaning of its basic expressions. ${ }^{2}$ In this way, the meaning of (1) 'Marie Curie is a physicist' is determined by the meaning of the name 'Marie Curie' and the predicate 'to be a physicist'. There are different ways to represent the semantic content of (1). ${ }^{3}$ A convenient way that I will adopt here is as the ordered pair 〈MC, PHYSICIST〉, such that 'MC' stands for Marie Curie herself and 'PHYSICIST' stands for the meaning of the predicate 'to be a physicist'.

As a semantic theory of proper names, Millianism has quite a few advantages. It captures intuitions that the truth-value of (1) depends solely on whether Marie Curie has the property of being a physicist - as opposed to rival theories that hold that (1) is true if, and only if, Marie Curie has uniquely identifying properties semantically encoded by the name 'Marie Curie', in addition to the property of being a physicist. ${ }^{4}$ It also correctly captures the modal profile of (1): in a world where Marie Curie is a pianist and was never interested in physics, (1) is false, even if in that world there is a physicist that resembles Marie Curie as she is in the actual world. ${ }^{5}$ Besides, Millianism is a simple theory, which is why it is also called 'Naïve Theory', and parsimony advises us to stick to simplicity whenever possible. Last but not least, echoing Salmon (1986, 121-2), "[The Millian Theory] has a prima facie claim on our endorsement", as "[e]ven Frege and Russell,

\footnotetext{
1 I will use 'meaning' and 'semantic content' interchangeably.

2 For notable exceptions, see Fine (2008); Putnam (1954).

3 See Braun (2005, 598, specially fn. 6), and King (2014).

4 See Dummett (1981); Frege (1892); Heck (1995); Russell (1910, 2001); Schiffer (1978); Strawson (1959).

5 See Kaplan (1989); Kripke (1980). For replies, see Dummett (1991); Evans (1979); Stanley (1997a,b, 2002).
} 
who argued in opposition to [Millianism], came to the philosophy of language with an initial predisposition toward something like [the Millian Theory]."

Several objections and criticisms to Millianism have emerged ever since it was proposed by John Stuart Mill (1893). ${ }^{7}$ It is impractical and outside the scope of this paper to try and survey all of them. Here I will focus on objections related to fictional names, that is, names of fictional characters, such as 'Superman', 'Sherlock Holmes', 'SpongeBob SquarePants', 'Princess Zelda', ${ }^{8}$ and the like. In particular, I will discuss objections related to the content of beliefs expressed by sentences with fictional names, such as 'Superman has impressive superpowers', 'SpongeBob SquarePants is goofy', 'Sherlock Holmes is a detective', etc. ${ }^{9}$ The central question of this paper is: what is the contribution of fictional names to the belief content of sentences of the form ' $f n$ is $\Phi$ ', such that ' $f n$ ' stands for any fictional name and ' $\Phi$ ' stands for a predicate?

The paper is organized as follows. I start by explaining what belief contents are according to Millianism and a first challenge fictional names raise: given that fictional characters do not exist like you, me, and Marie Curie (if they exist at all), what is the referent of fictional names? Then I explain and discuss two of the most common ways Millians have addressed the challenge, and argue that both have serious problems. After that, I argue for a different type of Millian Theory, which is a hybrid view in as much as it combines Millianism with a version of Fregeanism. In the last section, I will consider four objections to my view.

\section{Belief content}

Millianism is typically taken to be a theory about the belief content of proper names in addition to a theory about their meaning. It is not without

$6 \quad$ See also Braun $(1998,557-61$

$7 \quad$ For a small sample of objections, see Frege (1892); Heck (1995); Kripke (1979); Putnam (1975); Russell (1905); Schiffer (1992).

8 From the fantasy action-adventure video game The Legend of Zelda.

9 For an overview of the recent debate on the semantic content of fictional names see García-Carpintero (2019) 
reason that the meaning of names has been traditionally identified with their belief content. I will talk about some of them throughout the paper, but for now, suffice to give an intuitive reason. We pick and choose sentences to express our beliefs depending on their meaning. We also ascribe beliefs to others using sentences that we choose partially in virtue of their meaning. We say that people believe (what is expressed by) (1) 'Marie Curie is a physicist', and what is expressed by (1) is its meaning. So, it is just natural to take the meaning of linguistic expressions, like sentences, names, predicates, etc., to be the belief content they express. The idea that belief content is the meaning of a name, or at the very least part of it, is so pervasive in the literature that trying to talk about one without the other, or even questioning it, as I will, is quite unsettling. But I urge the reader to keep an open mind.

Following the tradition, the belief content of (1), according to Millianism, is just its semantic content, that is, 〈MC, PHYSICIST〉. It is natural to extend the same scheme to get the belief content of sentences with fictional names, and many Millians have done so. In this way, the belief content of 'Superman' is its referent, and the belief content of (2) 'Superman has impressive superpowers' is a content represented by the ordered pair 〈X, IMPRESSIVE SUPERPOWERS〉, such that ' $\mathrm{X}$ ' stands for the referent 'Superman', and 'IMPRESSIVE SUPERPOWERS' stands for the belief content of the predicate 'to have impressive superpowers' ${ }^{10}$ Here we have a first indication that fictional names may raise significant problems for Millianism: what is X? In other words, what is the referent and belief content of 'Superman', and fictional names in general?

Before I discuss possible answers, it is worth talking about different uses of fictional names to avoid the discussion to steer away from the main question. Philosophers working on the semantics of fictional names often distinguish three different uses of fictional names (García-Carpintero (2019)): textual, paratextual, and metatextual. A textual use of a fictional name is when the name is used in the story or to tell a story. A paratextual use is when a name is used to report what happens in the story - it is typically

10 I will not talk about the meaning of predicates in sentences with fictional names, but it is worth to point that they raise unique problems too-see Klauk (2014); Sawyer (2015). 
but not necessarily accompanied by the locution 'according to the story'. The metatextual use is when we use a name to talk about a fictional character outside the story, as in the sentence 'Superman has more impressive superpowers than Aquaman'. The distinction among uses of fictional names is relevant because philosophers disagree about whether there is a uniform account of the meaning of fictional names across them. Some philosophers argue that, in textual and paratextual context, the function of names is not to refer to an object like in ordinary cases. In these contexts, a speaker just pretends to refer and such uses of fictional names should not be treated as ordinary names like 'Marie Curie'. In metatextual contexts, however, it is less clear that there is some pretense involved, and there is good reason to extend the treatment of names like 'Marie Curie' to fictional names when used in this context. ${ }^{11}$ To avoid complications due to possible ramifications of the discussion, I will focus only on metatextual uses of fictional names.

There are two ways Millians can answer the question about the referent and belief content of fictional names (in metatextual uses). They can be anti-realists about fictional entities and hold that 'Superman' refers to nothing. In this view, fictional names are empty names. Or they can be realists and maintain that 'Superman' refers to an entity of some kind. I shall argue in the coming sections that both views have serious problems.

\subsection{Anti-realism about fictional characters}

An anti-realist view about fictional characters holds that fictional characters do not exist; not even as abstract entities. Anti-realism together with Millianism ('Anti-Realist Millian Theory', or 'ARM' for short) entails that fictional names do not have a referent. A proponent of $A R M$ does not necessarily hold that 'Superman' and other fictional names are not referring devices. Some proponents of $A R M$ accept that they are. It just happens that there is no object for the name to refer to or to pick out. In this view, fictional names are genuine empty names and lack belief content.

11 See García-Carpintero (2019) for an overview of some different combinations of semantic theories for different contexts. 
At first sight, $A R M$ might seem indefensible. ${ }^{12}$ For, it is natural to think that if 'Superman' does not have or express a belief content, then (2) 'Superman has impressive superpowers' does not express a belief content either. But this means that no one can believe (2) because there is no content to be believed, which is absurd. A lot of people believe (2). Braun (2005) has offered an extensive defense of $A R M$. In reply to the prima facie objection, he argues that (2) expresses a belief content even though 'Superman' lacks belief content. Its belief content is a "gappy" content that can be represented as _, IMPRESSIVE SUPERPOWERS〉, such that '_' stands for the lack of belief content of 'Superman'. In this view, the belief content of (2) is different from the belief content of (1) 'Marie Curie is a physicist' in as much as the former, but not the latter, is a gappy belief content. Nonetheless, Braun maintains, a gappy belief content is still a content that can be believed, known, etc. ${ }^{13}$

Aside from the initial objection, $A R M$ has been subject to many criticisms as a theory about the semantic content of fictional names. GarcíaCarpintero (2019) has recently offered an excellent and comprehensive overview of some of the main problems and possible replies. Here I want to focus strictly on problems related to gappy contents as the belief content of sentences with fictional names, and, in particular, with two pressing objections: The Transparency of Belief Content and The Problem of Conflating Unrelated Beliefs.

The Transparency of Belief Content objection is about the impossibility of rational people believing gappy belief contents. The objection is based on an intuitive claim that a belief content a person believes is transparent to her, in the sense that she is capable of recognizing the content of her belief. It is difficult to give a precise definition of 'transparency' in this sense, but for this paper suffice to know that it entails that someone who believes (and knows she believes) (1) recognizes that the content of her belief is $\langle\mathrm{MC}$, PHYSICIST〉. Moreover, if she also believes (3) 'Marie Curie was born in Poland', then she recognizes that the beliefs are about the same person. If

12 See Braun (2005), 597.

13 Following Kaplan's terminology, Braun calls this view 'The Gappy Proposition Theory', with 'proposition' being roughly synonymous to 'semantic content'. For terminological consistency, I will call it 'ARM' in this paper. 
belief contents are transparent in this sense, then, the objection goes, no rational person would believe a gappy belief content. For, when entertaining a gappy content, she would realize its "gappyness" and that it cannot be true. Consequently, she would refrain from believing it. Thus, if $A R M$ is right and (2) expresses a gappy belief content, then no one would believe it. But this is absurd because people, in fact, believe (2).

The second objection, The Problem of Conflating Unrelated Beliefs, is about ARM conflating beliefs that should be distinguished. Consider (2) and (4) 'Aquaman has impressive superpowers'. According to ARM, they express the same belief content, 〈_IMPRESSIVE SUPERPOWERS〉. However, there are at least three reasons to think that they express different belief contents. First, they express belief contents that are about different characters. The former is about the character of a story written by Jerry Siegel whereas the latter is about the character of a story written by Paul Norris and Mort Weisinger. The best way of accommodating this fact is by distinguishing the belief content of (2) and (4). Second, someone could rationally believe the former but not the latter. But if they express the same belief content, then someone who believes one necessarily believes the other. Thus, they should express different belief contents. Third, someone could rationally believe both (2) and (5) 'Aquaman does not have impressive superpowers'. But if (2) and (4) express the same belief content, then someone who believes (2) and (5) believes contradictory contents, which no rational person would do. Thus, (2) and (4) express different belief contents.

Braun's defense of $A R M$ against the criticisms above depends on his interpretation of a metaphysical analysis of belief commonly held by Millians, the Tripartite Theory of Belief (TTB), following Spencer's (2006) terminology. Since there are different versions of $T T B$, I will call Braun's version of 'Braun's Tripartite Theory of Belief' (BTTB).

Generally, TTB holds that a person $\mathrm{S}$ believes a belief content $\langle\mathrm{BC}\rangle$ if, and only if, $S$ is in a relation $R$ with $\langle\mathrm{BC}\rangle$ in one way or another. In Braun's version of $T T B$, the relevant relation is $S$ having a mental state M-BC the content of which is $\langle\mathrm{BC}\rangle$. The way the relationship is borne is the type of intrinsic mental state, that is, M-BC. In $B T T B$, a person believes $\prec \mathrm{MC}$, PHYSICIST $>$ if, and only if, she has a mental state M-MC the content of which is $\langle\mathrm{MC}$, PHYSICIST $\rangle$. According to Braun, 〈MC, PHYSICIST $\rangle$ is 
the content of M-MC because there is an appropriate causal relation between them. ${ }^{14}$ Braun argues that many different mental states can have the same content as M-MC. Having different mental states with the same content 〈MC, PHYSICIST $〉$ corresponds to believing it in different ways. If M$\mathrm{MC}$ and M-MS are mental states with the same content, then someone who has M-MC believes $\langle\mathrm{MC}$, PHYSICIST $\rangle$ in one way, say, in a Marie-Curie way, and someone who has M-MS believes the same content in a different way, say, in a Marie-Skłodowska way. These different ways of believing $\langle\mathrm{MC}, \mathrm{PHYSICIST}\rangle$ can correspond to believing (1) and (6) 'Marie Skłodowska is a physicist', respectively. Thus, someone can believe (1) without necessarily believing (6), provided she has M-MC but not M-MS. If someone has both M-MC and M-MS, "she believes the same content 'twice over', so to speak" (Braun, 1998, 575). Lastly, in BTTB, someone could rationally believe a content and its negation if they are believed in different ways and she does not realize her beliefs have contradictory contents. That is, someone can believe 〈MC, PHYSICIST $〉$ and its negation, 〈NOT, 〈MC, PHYSICIST $\gg$ if she believes the first in a Marie-Curie way and the latter in a Marie-Skłodowska way. It would not be rational, however, to believe both in the same way.

The way BTTB addresses The Transparency of Belief Contents is by assuring belief contents are not transparent. In this view, to believe (1) is to have the mental state M-MC that is causally related to Marie Curie. But this causal relation is "external" to the believer and there is nothing in the intrinsic mental state itself that indicates whether there is an object on the other end of the causal chain. If there is no object, the belief content of the mental state is gappy. But no introspective or a priori reasoning would reveal it. For this reason, someone who entertains a gappy belief content does not necessarily recognize its gappiness. Consequently, rational agents can believe gappy contents. ${ }^{15}$

14 The details of how and why «MC, PHYSICIST $〉$ is the belief content of M-MC should not concern us here.

15 Braun also argues that gappy contents can be true or false, contrary to the assumption in the objection that you would not believe gappy contents because they lack truth-value. I will leave this part of his reply aside to focus exclusively on issues about belief content. 
As for the second objection, BTTB undermines the reasons we have to distinguish the belief contents of (2) and (4). It explains how someone can rationally believe (2) but not (4). To believe the first is to have mental state M-SM and to believe the second is to have mental state M-AQ. Since these are different and independent mental states, one could have one without the other. Informally, this means that one can believe (2) but not (4) because one can believe __, IMPRESSIVE SUPERPOWERS > in a Superman way without believing it in an Aquaman way.

Braun's view also explains how someone can rationally believe both (2) and (5). Even though they express contradictory belief contents, someone can believe them in different ways. And she is rational if she does not realize her beliefs have contradictory contents.

Braun's reply to the Transparency of Belief Content objection is often accepted by Millians since many hold that belief contents are opaque. Unlike them, I am unsatisfied with the overall solution because I hold that belief contents are transparent. While I do not have a knock-down objection to this part of Braun's view, I join the opposition. I consider it a disadvantage and a motivation to look for an alternative theory.

The reply to the second objection, The Problem of Conflating Unrelated Beliefs, is clearly insufficient. I have offered three reasons for distinguishing the belief content of (2) and (4) but Braun has replies to only two of them, namely, the ones about attitudes we can have towards belief contents. He does not consider the first reason - about (2) and (4) being about different fictional characters. What is more, it might not have been an oversight on his part. In an earlier paper, Braun $(1998,561)$ has suggested that appealing to attitudes someone can take towards belief contents is the best argument one could offer to distinguish belief contents in instances of Frege's Puzzle, which is how he understands The Problem of Conflating Unrelated Beliefs $(2005,603)$. So, he must not take the first reason I offered as an argument worth discussing.

But I think it is a mistake to take The Problem of Conflating Unrelated Beliefs as an instance of Frege's Puzzle. While there are similarities between them, there are also significant differences that suggest they are distinct problems. One important difference is about the co-referential status of the names in question. In typical instances of Frege's Puzzle, there is no 
question about whether the names involved are co-referential. So much so that a proposed explanation that entails that 'Hesperus' and 'Phosphorus' do not refer to the same object (Venus) would be easily (and correctly) dismissed as nonsense. But the same is not true with the names 'Superman' and 'Aquaman'. It is not nonsense to hold that they refer to different entities. In fact, it is our intuition that Superman and Aquaman are different entities that leads us to hold that (2) and (4) have different belief contents and motivates many plausible theories about fictional entities. This difference is significant enough to set The Problem of Conflating Unrelated Beliefs apart from Frege's Puzzle. But Braun's theory ignores it.

In defense of Braun, one might reply that the argument I offered to distinguish the belief content of (2) and (4) is weaker than his. My argument is based on a "direct" intuition, and intuitions are known to be poor guides, whereas Braun's is based on a formal argument about the possibility of having contrasting attitudes towards (2) and (4). Therefore, there is no need to consider the argument based on direct intuitions. The objection can be put to rest once we appreciate the strength of our intuitions in ordinary cases. Consider how someone could argue that the sentences 'Roses are red' and 'Poppies are red' have different belief contents. She could simply say that they express different belief contents because the first is about roses, the second is about poppies, and these are different types of flowers. She does not and need not appeal to the fact that one could believe the first but not the latter. In fact, it would be rather unusual to offer it as a reason to distinguish their belief contents. Besides, in this case, an argument that appeals to contrasting attitudes someone can takes towards them seems weaker than one that simply points to the fact that roses are not poppies. This shows that, when an argument that appeals to this sort of intuition is available, it is stronger than an argument of the sort Braun offers. For this reason, the proposed argument based direct intuitions should not be dismissed.

Note that what I said here does not mean that Braun is wrong that the best argument to distinguish belief contents in typical instances of Frege's Puzzle appeals to the possibility of a competent speaker holding contrasting attitudes. He might be right about this. But if I am right, I have pointed out that the case with 'Aquaman' and 'Superman' is not a typical instance 
of Frege's Puzzle. Braun has failed to address a very powerful argument to distinguish the belief content of (2) and (4) and, consequently, The Problem of Conflating Unrelated Beliefs.

Perhaps an appropriate reply on behalf of $A R M$ now has to turn into a metaphysical discussion about in which sense, if any, Superman and Aquaman are different entities. Proponents of $A R M$ would have to argue that our intuitions that they are different can be somehow explained away. I do not wish to go into a metaphysical discussion because it would divert us from the main topic of the paper. I am content to end this section with a provisional conclusion that $A R M$ entails that (2) and (4) express the same belief content, which is unacceptable unless we explain away the intuition that Superman and Aquaman are different entities. Moreover, The Problem of Conflating Unrelated Beliefs cannot be dealt with in the same way as instances of Frege's Puzzle can, contrary to what Braun supposes.

\subsection{Realism about fictional characters}

The alternative to anti-realism is realism. A realist view about fictional characters maintains that Superman and other fictional characters exist as some sort of entity. What kind of entity fictional characters are is a matter of disagreement. Some philosophers argue that they are abstract artifacts of the same category as stories (Salmon (1995); Thomasson (1999, 2003); Voltolini (2006)). Others argue that they populate the Platonic heaven (Currie (1990); Wolterstorff (1980); Zalta (1988)). Yet, others argue that they are Meinongian entities (Parsons (1980); Priest (2011)) or possibilia (Lewis (1978)). For this paper it does not matter much which view one endorses as long as it meets two criteria: (a) Superman and Clark Kent are the same entity, like Marie Curie and Marie Skłodowska are the same person; and (b) Superman and Aquaman are different superheroes, like Marie Curie and Shirley Ann Jackson are different physicists. I will call the view that holds Millianism for fictional names and realism about fictional characters of 'Realist Millian Theory' $(R M){ }^{16}$

16 Everett, (2013, 188-204); García-Carpintero (2020); Kroon (2015), among others, have argued that assumption (a) - that Superman and Clark Kent are the same entity - raises unsurmountable problems for realist theories of fictional entities. 
Everett $(2013$, 188-204) argues that realists have consistently failed to and cannot offer criteria of identity for fictional characters to account for the fact that Superman and Clark Kent are the same entity. Garcia-Carpitero and Kroon argue that creationism, a popular branch of realism, entails that fictional objects are vague entities and, for that reason, claims about their identities are indeterminate. If these objections are on the right track, then there might not be a realist theory compatible with the assumption that Superman is Clark Kent, as I assume in this section.

I recognize the strength of the objections but there are suitable replies to them. Everett's objection depends on the claim that criteria of identity should be different for each type of entity. But Brody (2014) (convincingly, to me) argues against Everett's assumption. He defends that general criteria of identity that encompasses the Law of Identity, the Indiscernibility of Identicals, and the Identity of Indiscernibles, are good criteria of identity for all types of entities, including fictional entities: Superman is Clark Kent if, and only if, they share all properties. Brody further argues that the worry that such general principles are unsuitable because they are circular, uninformative, or philosophically uninteresting stems from misunderstandings. One of them is to think that, to know whether $a$ and b have all properties in common, one must first check $\mathrm{b}$ to see whether, like a, it has propety $\mathrm{F}$, for each property. Brody argues that this is incorrect. One can know that a and b have all properties in common by inferring from the fact that they have some properties in common, without, thereby, the need to check all of their properties. If Brody is right, Everett's objection does not undermine realist theories.

Garcia-Carpintero's and Kroon's objection depends on the claim that, according to creationism, there is no fact of the matter as to whether two vague entities are identical. For, a and b are identical if, and only if, they have all properties in common. But if some of a's properties are indeterminate, there is no fact of the matter (by definition) of whether a has them in common with b to establish their identity. What's more, properties that are indeterminate in the fictional world created by an author can be determinate in different ways for $a$ and $b$ in some alternative fictional world, thereby, proving that they are different entities.

While these claims might be true in some cases, I do not think they are true the case of Superman and Clark Kent and other pair of fictional entities the names of which are commonly used to illustrate Frege's Puzzle. Regarding the first claim, there is a fact of the matter as to whether Superman is Clark Kent: Siegel's intention that Superman has the property of being-identical-with-Clark Kent and that Clark Kent has the property of being-identical-with-Superman. They are the truth-makers of identity claims between Superman and Clark Kent (García-Carpintero, 2020, 186) and are good as any other truthmakers to establish their identity. About the second 
$R M$ doesn't have The Problem of Conflating Unrelated Beliefs. Since it meets criterion (ii), it holds that Superman and Aquaman are different entities. This entails that (2) 'Superman has impressive superpowers' and (4) 'Aquaman has impressive superpowers' express different belief contents; the former expresses 'SM, IMPRESSIVE SUPERPOWERS〉 and the latter, 〈AQ, IMPRESSIVE SUPERPOWERS〉, with 'SM' and 'AQ' standing for Superman and Aquaman themselves, respectively. But the view conflates related beliefs, so to speak, as a long-standing problem for Millianism arises: Frege's Puzzle. In the literature, we find different versions of Frege's Puzzle. Here I will discuss one version but my analysis should extend to other versions with some adjustments.

Intuitively, someone who does not know that Superman is Clark Kent could rationally believe (2) and (7) 'Clark Kent does not have impressive superpowers'. According to RM, such a person would believe a content and its negation. For, if 'Superman' and 'Clark Kent' are co-referential and have the same meaning, they make the same contribution to the belief content of (2) and (7), respectively. Besides, according to $R M$, (2) affirms that an object has the property of having superpowers while (7) denies it. Thus, someone who believes both (2) and (7) believes contents of the form $\mathrm{P}$ and

claim, if Superman and Clark Kent have some indeterminate properties, they could not be determinate in different ways in alternative fictional worlds. For, if there is one property that is determinate in different ways for Superman and Clark Kent, then Superman and Clark Kent will not share all properties. By the Indiscernability of Identicals, it entails that Superman and Clark Kent are not the same entity. But this leads to a contradiction. As I have just explained, Superman has the property of being-identical-with-Clark Kent and Clark Kent has the property of being-identical-with-Superman, which establishes that Superman is Clark Kent. Therefore, there cannot be a possible fictional world where Superman's and Clark Kent's properties that are indeterminate in the world created by Siegel are determinate in different ways.

Moreover, the problem raised by Garcia-Carpintero and Kroon does not arise to some creationist theories. See Paganini (2019) for a notable exception.

Of course, the issues presented in this footnote are not settled by this undoubtedly short discussion. But it shows that realists have ways of addressing common concerns against their view. 
$\neg \mathrm{P}$. But no rational person would knowingly believe blatantly contradictory contents. So, $R M$ is false.

There are possibly as many replies to Frege's Puzzle as there are Millians - and there are many Millians. It would be impractical to survey and consider all of them. Since most common replies rely on TTB, the Tripartite Theory of Belief - with some Millians even claiming that this is the only way to successfully explain Frege's Puzzle! ${ }^{17}$ - we can go a long way by taking a closer look at it.

To recap, TTB holds that to believe a belief content $\langle\mathrm{BC}\rangle$ is to be in a relation $\mathrm{R}$ with $\langle\mathrm{BC}\rangle$ in one way or another. In Braun's interpretation $(B T T B)$, the relation is to have a mental state, and the way in which the relation is borne is the specific (intrinsic) mental state the believer has. In this way, to believe $\langle\mathrm{MC}$, PHYSICIST $\rangle$ is to have a mental state M-MC the content of which is $\langle\mathrm{MC}$, PHYSICIST $\rangle$. Informally, to have M-MC is to believe $\langle\mathrm{MC}$, PHYSICIST $\rangle$ in a Marie-Curie way.

Salmon offers a different interpretation of TTB. He holds that to believe $\langle\mathrm{MC}, \mathrm{PHYSICIST}\rangle$ is to inwardly assent to it under a propositional guise. He does not explicitly say what a propositional guise is, but a common interpretation of his view takes them to be sentences (in a language). ${ }^{18} \mathrm{In}$ this interpretation, a guise of 〈MC, PHYSICIST〉 could be (1) 'Marie Curie is a physicist', or any other sentence that expresses the same content, such as (6) 'Marie Skłodowska is a physicist'. Here the relation R is to (inwardly) assent to a belief content under a (propositional) guise, and the way of being related with a belief content is a (propositional) guise. Replace propositional guises by ways of thinking or a sort of mode of presentation, and we have a version of TTB defended by Kaplan (1968) and Perry (1990).

Despite how Millians go about filling out the details of TTB, the reply to Frege's Puzzle (at least to the version I am considering here) is roughly the same: someone can rationally believe (2) and its negation (7) because she can believe the former in one way and believe the latter in a different way without realizing she believes contradictory contents (because belief contents are not transparent). In Braun's version of TTB, such a person believes 〈SM, IMPRESSIVE SUPERPOWERS〉, the belief content of (2) in

17 Salmon (1986, 111-13).

18 Braun and Saul (2002); Braun (2006). 
a Superman way (and she has mental state M-SM). But she believes its negation, 〈NOT, 〈SM, IMPRESSIVE SUPERPOWERS 〉, the belief content of (7), in a different way, namely, in a Clark-Kent way (and she has mental state M-CK). She would be irrational if she believed them in the same way; either in a Superman way or in a Clark-Kent way. But she does not.

In Salmon's view, such a person rationally believes «SM, IMPRESSIVE SUPERPOWERS〉 and its negation, 〈NOT, 〈SM, IMPRESSIVE SUPERPOWERS〉>, by assenting to them under different guises of SM. She believes the former under the guise of (2) and the latter under the guise of (7). But they are different guises; not only because (7) but not (2) has an expression of negation ('not') but, more importantly, because they have different names, 'Superman' and 'Clark Kent', respectively. When SM is presented to her under the guise of 'Superman', she believes «SM, IMPRESSIVE SUPERPOWERS > under the guise of (2). But she believes its negation under the guise of (7) when SM is presented to her under the guise of 'Clark Kent'.

Millians offer two reasons for why someone might not realize she believes contradictory contents when she believes (2) and (7). First, belief contents are not transparent. So no amount of introspection will reveal to her the content of her beliefs, and, therefore, that she believes contradictory contents. Second, she is not in a position to derive a contradiction from (2), (7), and (8) 'Superman is Clark Kent', in the syntactic sense, because she does not believe (8). To be clear, Millians do not deny that these sentences entail a contradiction. What is relevant in Frege's Puzzle cases is whether the person is in a position to derive or "see" the contradiction.

While Millian's line of reply is ingenious, it falls short of explaining some instances of Frege's Puzzle. In particular, instances where a person believes (8) and is aware that her beliefs are about the same person, as in the following case that I call 'SM vs. CK'. Suppose we are talking about superheroes who have impressive superpowers. You believe Aquaman is one of them and I vehemently disagree. We both agree that Superman has impressive superpowers. Then you ask my opinion about Clark Kent and I say: "Look, Superman does not use his superpowers while he is wearing regular clothes and pretending to be an ordinary journalist (his regular outfit, for short). So, even though Superman and Clark Kent are the same person and 
Superman has impressive superpowers, Clark Kent does not have impressive superpowers."

If one accepts SM vs. CK as a plausible scenario, then it is a case where I rationally believe (2), (7), and (8). However, RM holds that I am irrational, contrary to our intuitions, because I am in a position to realize I believe contradictory belief contents. For, given that I know that 'Superman' and 'Clark Kent' co-refer, I also know that (9) 'Clark Kent has impressive superpowers' follows from (2) and (8) by Leibniz's Law and that it entails a contradiction with (7).

Schiffer (1992) has offered a similar and by now famous criticism to Millianism, what he calls the "Fido'-Fido Theory'. He argues that someone can rationally believe (10) 'Lois believes that Superman has impressive superpowers' and (11) 'Lois does not believe that Clark Kent has impressive superpowers', even if she believes (8). But if RM is right, such a person would knowingly believe a content and its negation, which no rational person would do. So, Schiffer concludes, RM delivers the wrong verdict about our belief contents.

Salmon, Braun, and Braun \& Saul have addressed Schiffer's criticism. They argue that believing (8) is not enough to put the person in Schiffer's case in a position to realize she believes contradictory contents (in the syntactic sense). Salmon argues that to be in such a position a believer also has to believe that 'Superman' and 'Clark Kent' have the same meaning and make the same contribution to the belief content of (10) and (11). Without knowing it, she will not be in a position to derive a contradiction because she will not recognize that the inference from (10) and (8) to (12) 'Lois believes that Clark Kent does not have impressive superpowers' is an instance of Leibniz's Law and, therefore, legitimate. In fact, Salmon says, this is exactly the position Fregeans find themselves in: they know 'Superman' and 'Clark Kent' co-refer but not that they have the same meaning. ${ }^{19}$

Braun and Braun \& Saul agree with Salmon that the person in Schiffer's case is illogical because she lacks the disposition to use Leibniz's Law and swap names in (10) and (11). But, they add, she is rational provided that there is a good explanation for her lack of disposition. The kind of explanation

19 This is also how Salmon could reply to Bonardi's (ms) recent criticism to his view. 
they offer brings out background beliefs the person has. In Schiffer's case, they appeal to the person's predictions of Lois' behavior. For instance, if someone believes that Lois would say (2) but never (9) in reply to the question 'Which of your acquaintances have impressive superpowers?', it makes sense that she would refrain from swapping names in (10) and (11). She is making a logical mistake, which makes her illogical but not irrational. Note that, unlike Salmon, Braun and Braun \& Saul do not hold that she is ignorant of the meaning of 'Superman' or 'Clark Kent'. She might know it. But their view is that knowledge of their meaning does not prevent her from making logical mistakes.

Similar replies on behalf of Salmon, Braun, and Braun \& Saul could be offered to my objection based on SM vs. CK case. Salmon could say that I rationally believe (2), (7), and (8) because I am ignorant of the fact that 'Superman' and 'Clark Kent' have the same meaning and, therefore, belief content. Had I known it, I would not believe both (2) and (7). But Salmon's reply has a rather ad hoc flavor to it. He does not offer a principled reason to rule out the possibility of someone knowing the meaning of 'Superman' and 'Clark Kent' yet believing (2), (7), and (8). Clearly, this cannot happen if his view is correct. But why think that such a situation is at all impossible? As a matter of fact, I like to think that I am such a person. I accept that 'Superman' and 'Clark Kent' have the same meaning, yet I believe (2), (7), and (8) in SM vs. CK. So, even if ignorance of the meaning of 'Superman' and 'Clark Kent' can explain some cases where a person rationally believes contradictory belief contents, it does not explain all cases.

Following Braun's and Braun \& Saul's line of reply to Schiffer, they could say that in SM vs. CK I am illogical because I lack the disposition to use Leibniz's Law and swap names in (2) (or (7)) and (8). Nonetheless, I am rational because I believe a content and its negation in different ways and, they say, there is a plausible explanation as to why I do not realize I can swap names and derive a contradiction. But is there?

Indeed, Braun (2006) concedes it is difficult to come up with explanations in cases like SM vs. CK and does not offer a concrete case to support the claim that there is one. Someone might think that a possible explanation in SM vs. CK case can appeal to my predictions of my own behavior. If I believe that I would never say (9) in reply to the question 'Which fictional 
characters have impressive superpowers?', then it would be rational for me to refrain from swapping names in (2) and, thereby, not be in a position to derive a contradiction. Just like in Schiffer's case, I am illogical but rational because there is a plausible explanation for my lack of disposition.

Such a line of reply has at least two problems. First, it begs the question. It explains why I refrain from swapping names in (2) by appealing to the fact that I would never say (9). But the reason why I would never say (9), even though I believe (2) and (8), is that I refrain from swapping names is (2) in the first place. In sum, it explains my hesitation to use Leibniz's Law with (2) and (8) appealing to my hesitation to use Leibniz's Law with those sentences. This hardly constitutes an explanation.

Second, and perhaps more importantly, it is not true I would never say (9). There are cases where I am naturally disposed to swap names and say (9). Consider the following case, that I call 'Counting'. Suppose we are counting how many fictional entities I believe to have impressive superpowers among three: Aquaman, Superman, and Lex Luthor. Suppose further that I believe that Aquaman or Lex Luthor do not have impressive superpowers but that Superman does and that Superman is Clark Kent. Then you ask me if I believe (9) 'Clark Kent has impressive superpowers'. In this set up, I will be disposed to say both (2) and (9) for, at least, the following two reasons. Suppose, for reduction, that I do not believe (9). In this case, there would be one fictional entity of which I believe has impressive superpowers (Superman) and three of which I do not (Aquaman, Clark Kent, and Lex Luthor). But this totals four entities when we started with three. Thus, the assumption is false, and I must believe (9). Second, here we are counting entities with impressive superpowers. Because Superman only uses his superpowers when wearing his superhero outfit, it does not matter what I believe about him when he is wearing his regular outfits. What matters is what I think about him when he wears superhero outfits, and I believe he flies when wearing such outfits. This reinforces the claim that I believe (9) in Counting. ${ }^{20}$

20 SM vs. CK and Counting are intended to illustrate how context can interfere in how we assess the truth-value of belief ascription. Their purpose is similar to cases used to illustrate a contrast between de dicto/de re readings of belief ascriptions. Context determines what the correct interpretation of (10) is. In SM vs. CK, a de 
If one accepts Counting as a plausible case, then it is not true that I would never say (9) as Braun's and Braun \& Saul's explanation suggests. I would when counting how many fictional entities I believe have impressive superpowers. This undermines their explanation in SM vs. CK case because it shows that the explanation rests on the false claim that I would never say (9). One could reply to my objection saying that in Counting I am disposed to swap names because from one case to the other I changed my mind and came to believe (9). That is, before Counting, I would never say (9). But after Counting, I will always say (9) and never refrain from swapping names in (2). The problem with the reply is that it is false that I will always swap names in (2). I will still refrain from doing it whenever I find myself back in cases like SM vs. CK, where Superman's regular outfits are relevant to answer the question of who has impressive superpowers. So, saying that whenever we switch cases I change my mind is not the right analysis of the cases. A better explanation, I shall argue in the next section, is simply that which belief content 'Clark Kent' expresses depends on the context. In SM vs. CK case, it expresses a content that depends on how I think about Superman when he is wearing regular clothes and glasses. On the other hand, in Counting, it expresses a belief content that depends on how I think about Superman when he wears superhero outfits. Further, I believe (9) in the second case but not the first because only the belief content it expresses in the second case is in my belief box, so to speak. ${ }^{21}$

Proponents of $R M$ are bound to deny that either SM vs. CK or Counting, or even both cases make sense. But, aside from the problems they raise to traditional accounts of belief content of fictional names (and proper names, in general), the cases are plausible. More generally, they suggest that a theory that entails that I cannot believe (7) and (9) in different contexts will have problems to explain the contrast in my beliefs in SM vs. CK and Counting. But this should not be automatically taken to mean that

dicto reading is more appropriate; whereas in Counting, a de re reading captures the intuitions. But the resemblance of the cases stops here as I do not defend that the difference between de re and de dicto readings can be reduced to a distinction between evaluative perspectives.

21 I am using belief boxes simply as a metaphor to represent the belief relation. See the next section for an explanation. 
one or both cases are nonsense. If I am right, it suggests that we should revisit the assumption that the meaning of a name is its belief content. ${ }^{22}$

\section{A novel hybrid view}

The last section ended with a conclusion that SM vs. CK and Counting cases suggest that the belief content of 'Clark Kent' and (9) 'Clark Kent has impressive superpowers' may vary from context to context. At the same time, it is important to keep in mind that there are good reasons to keep the meaning of names the same across contexts because proper names are not context-dependent expressions like indexicals. ${ }^{23}$ To accommodate the seemingly contradictory data - that belief content but not meaning of names can change - I propose that we abandon the view that belief content of proper names is their meaning or even part of it. In the remainder of the paper, I will develop and argue for a view along these lines. In particular, I will propose a "hybrid theory", that is, a theory that embraces different theories for the meaning (or semantic content) and belief content of proper names.

For reasons mentioned at the beginning of the paper, I hold Millianism for the meaning of proper names. Thus, the meaning of 'Superman' is Superman himself, and 'Superman' and 'Clark Kent' have the same meaning. But I hold a version of Fregeanism for the belief content of names. More specifically, the belief content of a proper name is a bundle of finer-grained contents, both descriptive and non-descriptive contents, about the referent of the name with which they are associated. Belief contents are about the referent of the name either because the referent fits the descriptions in the belief content or because they are (somehow) causally related. For the sake of simplicity, I will use descriptive contents to explain and illustrate my view.

A belief content of a proper name is what is ordinarily thought to be a way of thinking of an object. In my view, the names 'Superman' and 'Clark Kent' can have different belief contents even though they have the same

22 The objection I developed here against $R M$ is not exclusive to Millian Theory. With adjustments, a similar objection can also be raised against Fregean Theories.

23 See Pelczar and Rainsbury (1998) for a defense of proper names as indexicals. 
meaning. The belief content of 'Superman' can be "the superhero who wears a red cape and blue pants"- «RED CAPE», for short — and the belief content of 'Clark Kent' can be "the reporter of the Daily Planet"- «REPORTER», for short. ${ }^{24}$ Precisely which belief content 'Superman' and 'Clark Kent' varies from person to person and from context to context. For someone who knows that Superman is Clark Kent, the belief content of 'Superman' and 'Clark Kent' could be the same, for instance, «RED CAPE». But for someone who knows Clark Kent but not his secret identity, they would be different contents.

The claim that the belief content of a name varies from person to person is fairly intuitive and not new. In Frege's famous footnote (1892, 210), he acknowledges that such variations are inevitable since different people may have different ways of thinking about the same object.

"In the case of an actual proper name such as 'Aristotle' opinions as to the sense may differ. It might, for instance, be taken to be the following: the pupil of Plato and teacher of Alexander the Great. Anybody who does this will attach another sense to the sentence 'Aristotle was born in Stagira' than will a man who takes as the sense of the name: the teacher of Alexander the Great who was born in Stagira."

It is also not hard to find philosophers who agree with Frege. On the other hand, the claim that context can influence the belief content of a name without affecting its meaning (and without a speaker changing her mind) has remained quite unexplored, although it has been suggested before by Wallace and Mason (1990) and briefly mentioned by Austin (1975, 142). If the conclusions reached at the end of section 2.2 are correct, they are right; the belief content of a proper name varies from context to context.

To explain precisely how context influences the belief content of names, I begin by laying out the metaphysics of belief my view suggests. For pedagogical purposes, I borrow the belief box metaphor to represent the belief

24 I will use double pointy brackets (' "' and '»') to enclose belief contents and to distinguish them from meaning (or semantic content), which are enclosed in single pointy brackets ('‘' and '〉'). 
relation. But it is important to note that my view does not depend on belief boxes being more than simply a metaphor.

In my view, not only names have belief contents, but also predicates, sentences, and other simple and complex expressions. The belief content of a sentence (in a context c) is a function of the belief contents of its meaningful parts (in c). What we find in belief boxes are belief contents of sentences, such as (C) «REPORTER, IMPRESSIVE SUPERPOWERS» and (S) «RED CAPE, IMPRESSIVE SUPERPOWERS». When a belief content is in a person's belief box, it represents the fact that she believes it. In contrast, when a belief content is outside her belief box, she does not believe it. According to SM vs. CK, I do not believe Superman has impressive superpowers when I think of him wearing regular outfits. Assuming this way is captured by the description "the reporter of the Daily Planet", it means that belief content (C) is outside my belief box. But I believe Superman has impressive superpowers when I think of him as wearing his superhero outfit. Assuming this way is captured by the description "the superhero who wears a red cape and blue pants", it means that $(\mathrm{S})$ is in my belief box. Figure 1 represents the state of affairs just described.

\section{Juliana's Belief Box \\ (S) «RED CAPE, SUPERPOWERS»}

(C) «REPORTER, SUPERPOWERS»

Figure 1

It should not be controversial that $(\mathrm{S})$ is in my belief box but $(\mathrm{C})$ is not; even Millians who disagree with me could accept it. The controversial claims are that (c) I do not believe (9) in SM vs. CK because (C) is outside my belief box; and (d) I believe (9) in Counting because ( $\mathrm{S}$ ) is in my belief box. For, according to the orthodox view - in which belief content is the meaning of names and the meaning of names is not context-sensitive -, if I (do not) believe (9), then I (do not) believe it across all contexts. Further, according to Millian Theory, I believe (9) if, and only if, «SM, SUPERPOWERS» is in my belief box. However, if my argument so far is on the right track, we have to revise the orthodox view because of contrasting intuitions in SM 
vs. CK and Counting. To argue for (c) and (d), I offer what I take to be an intuitive explanation of what changed from one case to the other to entail a change in the belief content of (9).

I submit that what changed from one case to another is how my mental life is evaluated or the perspective from which my belief box is evaluated, what I call an 'evaluative perspective'. By evaluative perspective I mean a point of view that determines a way of thinking of an object. It is that narrative, perspective, or explanation that naturally comes after you ask someone "Does Lois believe Clark Kent flies?" Often, and understandably, the answer is a variation of "It depends. From one point of view, yes. From another, no." Throughout the paper, I have mentioned two perspectives: the perspective of how I think of Superman with his reporter outfit and another of how I think of him with his superhero outfit. These perspectives determine «REPORTER» and «RED CAPE», respectively. ${ }^{25}$

If now we consider the question 'Does Juliana believe that Clark Kent has impressive powers?', we will get different answers depending on the evaluative perspective. From the first perspective (e'), I do not. Because from this perspective, the relevant belief content is (C) - it has «REPORTER», that is, the way I think of Superman with his reporter outfitsand it is not in my belief box. From the second perspective (e"), I do. Because from this perspective, the relevant belief content is $(\mathrm{S})$ - it has «RED CAPE», that is, the way I think of Superman with his superhero outfits - and (S) is in my belief box.

The suggestion that a belief box can be accessed and evaluated from different perspectives in the way just described should not be too controversial. So I will not argue for it here. I will now argue that whether I believe (9) depends on a perspective.

Echoing Wallace \& Mason (1990, 182), when we ascribe beliefs to people, including ourselves, we typically do not do so without also bringing forward a narrative or other relevant background information. To appreciate their suggestion, consider again how ordinary people answer questions like 'Does Lois Lane believes Clark Kent can fly?' or 'Does Lois Lane believe Superman

25 There are many more perspectives from which my belief box can be evaluated, such as the perspective of any way of thinking of Superman, the perspective of how I think Lois thinks of Superman when he wears regular outfits, etc. 
is a reporter?' The answer is typically not a simple "yes" or "no". It often comes with a narrative or some relevant background information to put the answer into perspective (in the ordinary sense), such as: "no, Lois does not believe Clark Kent can fly because she does not know he is Superman"; or "yes, she believes Superman is a reporter because she believes Clark Kent is a reporter, and they are the same person. But she would never use the sentence 'Superman is a reporter'. So do not ask her 'Write an article with Superman' if you want her to collaborate with Clark Kent". Narratives naturally narrow down how a belief ascription should be interpreted to avoid confusions like those that give rise to Frege's Puzzle. The fact that we ordinarily use narratives suggests that we recognize that without clarification a belief ascription may be puzzling or ambiguous because it can be "seen" from different perspectives.

Bringing evaluative perspectives to determine whether a person believes what is expressed by a sentence legitimizes the role of narratives and background information already have when we talk about a person's mental life. Once we acknowledge that such narratives intuitively play this role, it is not hard to see that different narratives may yield different verdicts with respect to whether someone believes what is expressed by a sentence. Evaluative perspectives capture essential information in narratives and background information to evaluate a belief ascription.

I can now explain what changed from SM vs. CK and Counting: the evaluative perspective in the narratives. The evaluative perspective that correctly captures the narrative in SM vs. CK case is e'. The narrative there is the explanation I offer for why I say I do not believe (9), namely, because Superman does not use his superpowers when wearing regular outfits. I make explicit that I am talking about my belief box (that is, what I believe) in light of the fact that Superman has different types of outfits, behaves in different ways depending on which type he wears, and focusing on one type of outfit. To determine whether I believe (9) in this narrative, my belief box should be evaluated from a perspective of how I think of Superman (or Clark Kent, they are the same entity, after all) when he wears regular outfits. Such a perspective is e'. Since e' determines a belief content outside my belief box, I do not believe (9) with respect to e'. Informally, I do not believe (9) in SM vs. CK case. 
In contrast, the evaluative perspective that correctly captures the narrative in Counting is e". The narrative here is that we are counting fictional entities that have a certain property typically exhibited when they wear superhero outfits. I make explicit that I am talking about my belief box in light of the fact that Superman has different types of outfits, behaves in different ways depending on which type he wears, and focusing on the superhero outfit. To determine whether I believe (9) in this narrative, my belief box should be evaluated from a perspective of how I think of Clark Kent when he wears superhero outfits. This time e" captures such a narrative. Since e" determines a belief content inside my belief box, I believe (9) with respect to e". In other words, I believe (9) in Counting.

Before I continue, let me consider a natural alternative explanation of the cases. One might think that the belief content of (9) should be fixed to (C) (at least for me) and hold that what changed from one case to another is where $(\mathrm{C})$ is relative to my belief box. $(\mathrm{C})$ is outside my belief box in SM vs. CK but inside it in Counting. In this way, the suggestion goes, our intuitions are explained without appealing to a controversial claim that the belief content of (9) is contextually determined. The problem with this suggestion is that changing which belief contents are inside or outside my belief box represents the fact that I have changed my mind from one case to another. But, as I have argued before, this is an incorrect explanation.

How can evaluative perspectives explain Frege's Puzzle and rescue RM? To recap, the problem is to explain how one could rationally believe (2) 'Superman has impressive superpowers' and (7) 'Clark Kent does not have impressive superpowers', given that Millianism entails that they have contradictory meanings. In my view, these sentences have contradictory meanings because I take Millianism to be the correct theory about the meaning of fictional names. But they do not necessarily have contradictory belief contents. If the narratives surrounding (2) and (7) are captured by different perspectives that determine different ways of thinking of Superman, one would not believe a content and its negation and the puzzle disappears. ${ }^{26}$

26 Overall, there are three ways to explain from where the two perspectives come. One is to explain that the difference in the perspectives of (2) and (7) comes from the fact that they are considered in different contexts with different narratives. Another suggestion is to hold that they are considered in the same context with two 
The narratives surrounding (2) and (7) (and in typical instances of Frege's Puzzle) are indeed captured by different perspectives that point to different belief contents. Part of the puzzlement in these cases comes from the fact that we recognize that the use of different but coreferential names to express beliefs with apparent contradictory contents indicates that a point is being made about two different ways of thinking of the same object. To formally capture this, I use different evaluative perspectives that determine different belief contents to evaluate whether someone believes (2) and (7). Thus, a person who believes (2) and (7) does without believing contradictory contents. ${ }^{27}$

My proposed view differs from current Millian Theories in many ways. First, in my view, belief contents are not pragmatically conveyed when someone utters a sentence (Salmon (1986)). I do not deny that they could be pragmatically communicated in some cases. But even when they are, it is not what explains our intuitions about whether we believe the content of a sentence. Second, in my view, we have a simple metaphysics of belief according to which the belief relation is a two-place relation between belief content and a person. Translating it to the belief box metaphor, to believe $\langle\mathrm{BC} »$ is to have $\langle\mathrm{BC} »$ in one's belief box. Thus, my view is not a version of TTB. This sets it apart from most common versions of Millianism. ${ }^{28}$ Besides, it is compatible with my view and the overall explanation of the cases that belief contents are transparent, which is not the case with many common versions of Millianism. Lastly, my view is not another version of pluralist views about meaning. As I have emphasized, belief contents are not the meaning or part of the meaning of names. I hold Millianism for the meaning of names, which is not a pluralist theory.

different narratives. A third way is to hold that one narrative can have different perspectives. I find the second option more plausible because it fits with how we ordinarily understand contexts. But I will not argue for it here.

27 A similar explanation is available to solve Kripke's puzzle about beliefs and Mates's problem with multiple iterations of attitude ascriptions. For lack of space, I will leave it to the reader to work out the details.

28 Braun (2005); Braun and Saul (2002); Kaplan (1968); Perry (1990); Salmon (1986). 


\section{Objections}

Here I will consider four pressing objections to my account. First, one might object that, in my view, no two people believe the same belief content. Thus, it is never true that two people, say, Lois Lane and I, believe (2) 'Superman has impressive superpowers'. But of course, we can both believe it. So, my view is false.

It is true that, in my view, there is a sense in which no two people have the same belief when they both believe (2). But this is an advantage. As Frege and other philosophers recognized (see quote on p. 155), the way of thinking of an object can and often varies from person to person. My view captures this intuition by holding that belief contents vary from person to person. But, in my view, it is also true that Lois Lane and I believe (2), provided that our belief boxes are evaluated from a common and appropriate evaluative perspective. For instance, it is false that we believe (2) from a perspective e" of how I think of Superman ${ }^{29}$ when he wears superhero outfits. Perspective e" determines my belief content, «RED CAPE», and, assuming that Lois Lane does not think of Superman in my way, she will not have the same belief content in her belief box. But it can be true from a perspective e"" of how a believer thinks of Superman when he wears a superhero outfit. Such a perspective will point to different belief contents for each of us. Assuming that these belief contents are in our respective belief boxes, Lois Lane and I believe (2) in e"', accommodating the intuitions brought up by the objection.

A second worry one might have is regarding naming belief contents. There does not seem to be anything preventing us from naming belief contents. In this case, belief contents will be the meaning of certain names which contradicts the claim that belief contents are not the meaning of names.

Contrary to the objection, my view can accommodate the fact that belief contents can be named. «RED CAPE» can be the meaning of a name, as long as it is not also its belief content. If we name «RED CAPE» of 'Patrick' and refer to it by using this name, then my view predicts that its belief

29 Braun (2005); Braun and Saul (2002); Kaplan (1968); Perry (1990); Salmon (1986) 
content is another content; a way of thinking of «RED CAPE». But it does not prevent belief contents from being named.

This brings us to a third objection. There is a close relationship between belief ascriptions with that-clauses and those without, such as the pair (13) 'Juliana believes 'Clark Kent has impressive superpowers", that I have been discussing throughout this paper, and (14) 'Juliana believes that Clark Kent has impressive superpowers'. If the truth-value of the first depends on an evaluative perspective, as I argued it does, it is natural to expect the truthvalue of the second to also depend on it. But how could that be?

Following Predelli (2005), I propose that evaluative perspectives enter as parameter of evaluations of (14). This entails that their truth-value is relativized to both worlds and evaluative perspectives - and possibly other parameters, such as time depending on the view one holds. Thus, (14) gets its truth-value with respect to not only a world but also an evaluative perspective. When it is evaluated with respect to the actual world and perspective e', (14) is false. When it is evaluated with respect to the actual world and perspective e", it is true. Note that, even though (14) has the same meaning in both cases, the difference in truth-value its gets in different perspectives does not entail a contradiction. Since its truth-value is relativized to evaluative perspectives, a contradiction follows from a sentence getting different truth-values with respect to the same evaluative perspective (possible world, etc.), which is not the case here.

Lastly, one could argue that relativizing the truth-value of belief ascriptions is ad hoc. It is not far fetched to expect that all sentences should be relativized to the same parameters. Here I have offered some reasons to add evaluative perspectives to the parameters of evaluation of belief ascriptions. But there does not seem to be a reason to add them to parameters of evaluation of simple sentences, such as (9) or (2). So my view should be rejected.

The concern is legitimate, but it can be put to rest. Predelli (2005), Searle (1980), and Travis (1989) have argued that simple sentences should also be evaluated with respect to something like an evaluative perspective. To briefly explain the sorts of considerations that led them to such a conclusion, consider the following case discussed by Predelli (2005, 174-5). Take the sentence (15) 'Bill cut the grass'. (15) is a perfectly good example of a sentence with no context-sensitive expression, aside from tense. As 
such, it is expected to have the same truth-value across contexts within the same possible world. Now suppose that Bill employed a pair of scissors to separate each leaflet roughly perpendicular to the ground. Is (15) true or false? Despite appearances, it depends on the context. In a context where Bill's partner asked him to mow the lawn, (15) is false. From this perspective, only shortening the blades by slicing them along a direction roughly parallel to the ground is to cut the grass. In a context where Bill's partner demands that the number of grass blades in their garden is doubled by parting each leaflet in two, (15) is true. From this perspective, Bill cut the grass. So, even simple sentences like (15) need to be evaluated from some sort of perspective. Of course, here the perspective has less to do with way of thinking of objects and more with what counts as cutting the grass.

By bringing this case, I do not mean to suggest that there are not alternative accounts for the phenomenon. There are many of them. ${ }^{30}$ My point is to show that there is a case to be made that the truth-value of simple sentences should be relativized to an evaluative perspective - shortening the blades or doubling the number of grass blades. In this case, my proposal would not be ad hoc, contrary to what the objection suggests.

\section{Final remarks}

I have argued that the cases considered here suggest that the belief content of a proper name (and a sentence it is part of) depends on an evaluative perspective and should be relativized to contexts. But I have not said much about the meaning of fictional names. And it is crucial to evaluate my view to know what the meaning of fictional proper names is - an abstract entity of some kind or are they empty names? The reason I have not said much about the meaning of fictional proper names is that I wanted to focus on their belief content and argue for a distinction between meaning and belief content of proper names. I then endorsed Millianism for the meaning of proper names. The issues with which I began this paper and that would require to take a stance and side with $A R M$ or $R M$ do not arise in my view

30 See Berg (2002); Borg (2004); Cappelen and Lepore (2005); Recanati (2004); Stanley and Szabó (2000) for a few sample of alternative views. 
because of the distinction I make. I have an inclination towards $R M \cdot{ }^{31}$ But it is important to notice that, in principle, both views could be accommodated within my proposed framework of belief contents.

\section{References}

Austin, John L. 1975. How to Do Things with Words. Oxford University Press. https://doi.org/10.1093/acprof:oso/9780198245537.001.0001

Berg, Jonathan. 2002. "Is Semantics Still Possible?" Journal of Pragmatics 34 (4): 349-59. https://doi.org/10.1016/s0378-2166(01)00044-3

Bonardi, Paolo. ms. "Salmon, Schiffer and Frege's Constraint".

Borg, Emma. 2004. Minimal Semantics. Oxford University Press. https://doi.org/10.1093/0199270252.003.0006

Braun, David. 1998. "Understanding Belief Reports". The Philosophical Review 107 (4): 555-95. https://doi.org/10.2307/2998375

Braun, David. 2005. "Empty Names, Fictional Names, Mythical Names". Nô̂s 39 (4): 596-631. https://doi.org/10.1111/j.0029-4624.2005.00541.x

Braun, David. 2006. "Illogical, but Rational". Noûs 40 (2): 376-79. https://doi.org/10.1111/j.0029-4624.2006.00616.x

Braun, David and Saul, Jennifer. 2002. "Simple Sentences, Substitutions, and Mistaken Evaluations". Philosophical Studies 111 (1): 1-41. https://doi.org/10.1023/A:1021287328280

Brody, Baruch A. 2014. Identity and Essence. Princeton University Press.

Cappelen, Herman and Lepore, Ernest. 2005. Insensitive Semantics: A Defense of Semantic Minimalism and Speech Act Pluralism. Blackwell. https://doi.org/10.1002/9780470755792

Currie, Gregory. 1990. The Nature of Fiction. Cambridge University Press. https://doi.org/10.1017/CBO9780511897498

Dummett, Michael. 1981. Frege: Philosophy of language. Harvard University Press.

Dummett, Michael. 1991. The Logical Basis of Metaphysics. Harvard University Press.

Evans, Gareth. 1979. "Reference and Contingency". The Monist, 161-189. https://doi.org/10.5840/monist197962220

Everett, Anthony. 2013. The Nonexistent. Oxford University Press. https://doi.org/10.1093/acprof:oso/9780199674794.001.0001

Fine, Kit. 2008. Semantic Relationism. The Blackwell Brown Lectures in Phiosophy. Blackwell Publishing. https://doi.org/10.1002/9780470690826

31 See fn. 16. 
Frege, Gottlob. 1892. "Sense and Reference". The Philosophical Review 57 (3): 209-30.

García-Carpintero, Manuel. 2019. "Semantics of Fictional Terms". Teorema 38 (2): $73-100$.

García-Carpintero, Manuel. 2020. "Referential Indeterminacy in Fiction". Journal of Applied Logics-IfCoLoG Journal of Logics and their Applications (7) 2: 177-90.

Heck, Richard G. 1995. "The Sense of Communication". Mind 104 (413): 79-106. https://doi.org/10.1093/mind/104.413.79

Kaplan, David. 1968. "Quantifying In". Synthese 19 (1-2): 178-214. https://doi.org/10.1007/bf00568057

Kaplan, David. 1989. "Demonstratives". In Themes from Kaplan, edited by Joseph Almog, John Perry, and Howard Wettstein, 481-563. Oxford: Oxford University Press.

King, Jeffrey C. 2014. "Naturalized Propositions". In New Thinking About Propositions, edited by Jeffrey C King, Scott Soames, and Jeff Speaks, 47-70. Oxford University Press. https://doi.org/10.1093/acprof:oso/9780199693764.003.0004

Klauk, Tobias. 2014. "Zalta on Encoding Fictional Properties". Journal of Literary Theory 8 (2): 234-56. https://doi.org/10.1515/jlt-2014-0012

Kripke, Saul. 1979. "A Puzzle About Belief". In Meaning and Use. Edited by Avishai Margalit. Dortrecht: Kluwer. 239-83. https://doi.org/10.1093/acprof:oso/9780199730155.003.0006

Kripke, Saul. 1980. Naming and Necessity. Oxford: Blackwell. https://doi.org/10.1007/978-94-010-2557-7_9

Kroon, Fred. 2015. "Creationism and the Problem of Indiscernible Fictional Objects". In Fictional Objects, edited by Stuart Brock and Anthony Everett, 147 173. Oxford University Press. https://doi.org/10.1093/acprof:oso/9780198735595.003.0007

Lewis, David. 1978. "Truth in Fiction". American Philosophical Quarterly 15 (1): 37-46. https://doi.org/10.1093/0195032047.003.0015

Mill, John S. 1893. A System of Logic, Ratiocinative and Inductive: Being a Connected View of the Principles of Evidence and the Methods of Scientific Investigation. New York: Harper \& Brothers.

https://doi.org/10.1017/cbo9781139149839

Paganini, Elisa. 2019. "Vague Fictional Objects". Inquiry. https://doi.org/10.1080/0020174x.2019.1610050

Parsons, Terence. 1980. Nonexistent Objects. Yale University Press.

Pelczar, Michael and Rainsbury, Joe. 1998. "The Indexical Character of Names". Synthese 114 (2): 293-317.

Perry, John. 1990. "Frege on Demonstratives". In Demonstratives, edited by Palle Yourgrau, 50-70. Oxford University Press. https://doi.org/10.2307/2184564 
Predelli, Stefano. 2005. Contexts: Meaning, Truth, and the Use of Language. Clarendon Press. https://doi.org/10.1093/0199281734.001.0001

Priest, Graham. 2011. "Creating Non-Existents". In Truth in Fiction, edited by Franck Lihoreau, 107-18. Ontos Verlag. https://doi.org/10.1515/9783110326796.107

Putnam, Hilary. 1954. "Synonymity, and the Analysis of Belief Sentences". Analysis 14 (5): 114-22. https://doi.org/10.1093/analys/14.5.114

Putnam, Hilary. 1975. "The Meaning of 'Meaning'". In Mind, Language, and Reality: Philosophical Papers, volume 2, 215-71. Cambridge University Press. https://doi.org/10.1017/cbo9780511625251.014

Recanati, François. 2004. Literal Meaning. Cambridge University Press. https://doi.org/10.1017/cbo9780511615382

Russell, Bertrand. 1905. "On Denoting". Mind 14 (56): 479-93.

Russell, Bertrand. 1910. Knowledge by acquaintance and knowledge by description. Proceedings of the Aristotelian Society (11): 108-28.

Russell, Bertrand. 2001. The Problems of Philosophy. Oxford University Press.

Salmon, Nathan. 1986. Frege's Puzzle. Ridgeview Publishing Company, Atascadero, California.

Salmon, Nathan. 1995. "Being of Two Minds: Belief With Doubt". Nô̂s 29 (1): 120. https://doi.org/10.2307/2215724 Reprinted in Salmon, N. U. (2007). Content, Cognition, and Communication: Philosophical Papers II, volume 2, 23048. Clarendon Press.

Sawyer, Sarah. 2015. "Fictional Objects". In Fictional Objects, edited by S. Brock and A. Everett, 208-29. Oxford: Oxford University Press.

Schiffer, Stephen. 1978. "The Basis of Reference". Erkenntnis :13 171-206. https://doi.org/10.1007/bf00160893

Schiffer, Stephen. 1992. "Belief Ascription". The Journal of Philosophy 89 (10): 499-521. https://doi.org/10.2307/2941005

Searle, John R. 1980. "The Background of Meaning". In Speech Act Theory and Pragmatics. Edited by John Searle, Ferenc Kiefer and Manfred Bierwisch. Dordrecht: D. Riedel. 221-32. https://doi.org/10.1007/978-94-009-8964-1_10

Spencer, Cara. 2006. "Do Conversational Implicatures Explain Substitutivity Failures?". Pacific Philosophical Quarterly 87 (1): 126-39. https://doi.org/10.1111/j.1468-0114.2006.00250.x

Stanley, Jason. 1997a. "Rigidity and Content". In Language, Thought, and Logic: Essays in Honour of Michael Dummett, edited by Richard G Heck, 131-56. Oxford: Oxford University Press.

Stanley, Jason. 1997b. "Names and Rigid Designation". In Companon to the Philosophy of Language, edited by Bob Hale and Crispin Wright, 555-86. Oxford: Blackwell Publishing. https://doi.org/10. 1002/9781118972090.ch36 
Stanley, Jason. 2002. "Modality and What Is Said". Philosophical Perspectives 16: 321-44. https://doi.org/10.1111/1468-0068.36.s16.12

Stanley, Jason and Szabó, Zoltan Gendler. 2000. "On Quantifier Domain Restriction". Mind and Language 15 (2-3): 219-61. https://doi.org/10. 1111/14680017.00130

Strawson, Peter F. 1959. Individuals: An Essay in Descriptive Metaphysics. London: Methuen. https://doi.org/10.4324/9780203221303

Thomasson, Amie L. 1999. Fiction and Metaphysics. Cambridge University Press. https://doi.org/10.1017/cbo9780511527463

Thomasson, Amie L. 2003. "Speaking of Fictional Characters". Dialectica 57 (2): 205-23. https://doi.org/10.1111/j.1746-8361.2003.tb00266.x

Travis, Charles. 1989. The Uses of Sense: Wittgenstein's Philosophy of Language. Oxford: Clarendon Press. https://doi.org/10.1093/0199245878. 001.0001

Voltolini, Alberto. 2006. How Ficta Follow Fiction. Springer.

Wallace, John and Mason, HE. 1990. "On Some Thought Experiments About Mind and Meaning". In Propositional Attitudes: The Role of Content in Logic, Language, and Mind, edited by Joseph Owens and Anthony C. Anderson, 175200. Chicago University Press.

Wolterstorff, Nicholas. 1980. Works and Worlds of Art. Oxford: Clarendon Press. https://doi.org/10.1007/1-4020-5147-6

Zalta, Edward. 1988. Intensional Logic and the Metaphysics of Intentionality. MIT Press. 